\title{
"Assinatura quotidiana da minha escritura com a morte": a relação de Bandeira e Pessoa com a noite
}

\author{
"Assinatura cotidiana da minha escritura com a morte": the relationship of \\ Bandeira and Pessoa with the night
}

\author{
Letícia Cristina Alcântara Rodrigues ${ }^{2}$ \\ Universidade Federal de Goiás, Goiânia, GO, Brasil.
}

\begin{abstract}
Resumo: Dois grandes representantes do movimento modernista de seus países, Manuel Bandeira (1886-1968) e Fernando Pessoa (18881935), contemporâneos, apresentam uma forma peculiar de representação da morte em seus escritos. Bandeira a tem como leitmotiv de sua produção, enquanto Pessoa sutilmente a insere em sua poesia seja por meio de seu ortônimo ou seus heterônimos, às vezes com certa ironia, outras com naturalidade. Nesse sentido, este trabalho tem por princípio estudar a "escritura com a morte" analisando alguns poemas dos escritores que remetem a esse tema, em especial, aqueles que utilizam a noite como sinônimo/metáfora dele, apoiando-se nos diálogos de Berenice Berardinelli, Donaldo Schüler, Antônio Cândido, Gaston Bachelard e Octavio Paz, no sentido de procurar pontos de encontros entre essas poéticas noturnas de morte.

Palavras-chave: Modernismo. Manuel Bandeira. Fernando Pessoa. Noite. Morte.

Abstract: Two great names of the modernist movement in their respective countries, Manuel Bandeira (1886-1968) and Fernando Pessoa (1888-1935), being contemporary, have both a peculiar way representing death in literature. Bandeira has it as a leitmotiv of his work, while Pessoa subtly inserts in his poetry, either through his orthonymous or heteronyms, sometimes with irony, and sometimes naturally. In this sense, this present work begins by studying the "escritura com a morte", with the analyzis of some poems by writers who refer to this theme, especially those who use the night as a synonym / metaphor, relying on the dialogue with Berenice Berardinelli, Donaldo Schüler, Antônio Cândido, Gaston Bachelard and Octavio Paz, seeking encounters between these nocturnal poetics of death. Keywords: Modernism. Manuel Bandeira. Fernando Pessoa. Night. Death.
\end{abstract}

\section{Introdução}

\author{
"Dêem-me os óculos \\ Para ver a morte \\ Encará-la de perto \\ E tocar-lhe a alma \\ Num abraço forte \\ Para toda a vida" \\ (Fernando Pessoa)
}

Dois grandes representantes da língua portuguesa e também do movimento modernista, Manuel
Bandeira, brasileiro, nascido em 19 de abril de 1886, em Recife, e Fernando Pessoa, português, nato em Lisboa, no dia 13 de junho de 1888, além de contemporâneos, apresentam uma forma peculiar de representação da morte em seus escritos. Bandeira a tem como leitmotiv, enquanto Pessoa e seus heterônimos inserem-na em suas obras às vezes como enigma, outras com naturalidade e respeito.

Ambos os poetas utilizam como sinônimo do tema da morte imagens noturnas, atribuindo-lhes ambivalências e força lírica. Nesse sentido, o presente trabalho, apoiado principalmente nos apontamentos

SOARES, Bernardo. Não compreendo senão como uma espécie de falta de asseio... In: PESSOA, Fernando. Livro do Desassossego: composto por Bernardo Soares, ajudante de guarda-livros na cidade de Lisboa. ZENITH, Richard (Org.). São Paulo: Companhia das Letras, 1999. 2 http://orcid.org/0000-0002-3480-7393. E-mail: letycrys@gmail.com 
de Berenice Berardinelli, Donaldo Schüler, Antônio Cândido, Gaston Bachelard e Octavio Paz, tem como princípio estudar o cotejo e encontros desses poetas com a morte evocada, especialmente, pelas imagens noturnas, para tratar a finitude terrena.

\section{A poesia de Manuel Bandeira e Fernando Pessoa}

\author{
"Falta a morte chegar... Ela me espia \\ Nesse instante talvez, mal suspeitando \\ Que já morri quando o que fui morria”.
} (Manuel Bandeira - Noturno do Morro do Encanto)

Manuel Bandeira, poeta, crítico literário e de arte, tradutor e professor pernambucano. Sua extensa carreira e produção transpassa os primeiros anos do Modernismo brasileiro, levando o poeta a outro patamar na produção artística. Sua poesia é descrita por Gilda de Mello e Souza e Antônio Cândido (1993) como condensada, simples e de espontânea naturalidade.

Poeta de várias temáticas, ele recorre a diversas imagens para transmitir a sua subjetividade, criando um "eu-lírico" único e profundo que parece "brincar" entre um e outro símbolo. Assim, além da noite, é recorrente em Bandeira a imagem da estrela, do oceano, da lua, que tratam das temáticas do amor, do cotidiano e da memória.

Essas imagens, nem sempre nomeadas em seus poemas, ganham formas e novos significados nas mãos do poeta, que se dizia menor, à medida que a poesia de Bandeira avança para a maturidade, que é alcançada em sua terceira fase. Essa é caracterizada pelo refinamento técnico, com a convivência pacífica entre a tradição e o moderno, de versos métricos e rimados a versos livres e brancos. Com relação à primeira e à segunda fase, essa é um período de transição, enquanto aquela é desenhada pela poesia tradicional, com versos alexandrinos predominando, entretanto, pode-se sentir certo experimentalismo de técnicas da vanguarda europeia (FORESTI, 2001). Nessa tríade, a crítica divide a sua obra em A cinza das horas (1917), Carnaval (1919) e O ritmo dissoluto (1924) como representantes da primeira fase, Libertinagem (1930) e Estrela da manhã (1936) pertencendo à transição e Lira dos cinquent'anos (1940), que marca a sua maturidade.

Com relação à segunda fase de Bandeira, podemos vê-la já iniciada em $O$ ritmo dissoluto, como o próprio poeta expressa, em uma entrevista/conversa com Paulo Mendes Campos:

\begin{abstract}
"A maioria dos poemas do livro", fala Manuel Bandeira, "estão escritos numa forma que ainda não é o verso livre $100 \%$. Há neles ainda um certo senso métrico, em ritmos como que desmanchados, dissolvidos (dissolutos). Dai o título" (1949, p. 124).
\end{abstract}

Fernando Pessoa, que disse em um de seus poemas não saber quantas almas possuía ${ }^{3}$, é, conforme Donaldo Schüler (1966, p. 63) "poeta no plural, é poetas. E os poetas em que se desdobra Fernando Pessoa cultivam muitos gêneros: lírica, épica, teatro, ensaio, epistolografia. Oferecem contrastes violentos”. Sua poesia é considerada de linguagem precisa e simples, porém desafiante do raciocínio, aguçando o imaginário do leitor com versos curtos e orações breves, tornando-se grande "na vivência e na expressão do humano com profundidade e amplitude" (SCHÜLER, 1966, p. 78).

"Poeta dramático", como se intitulava, Pessoa criou mais de setenta heterônimos, tornando-se, como expressa Massaud Moisés (1988, p. 47), um "dos casos mais complexos e estranhos, se não único, dentro da literatura portuguesa" ${ }^{\prime \prime}$, uma vez que pouco

\footnotetext{
3 "Não sei quantas almas tenho/ Cada momento mudei./ Continuamente me estranho./ Nunca me vi nem achei./ De tanto ser, só tenho alma." (PESSOA, Fernando. Não sei quantas almas tenho. Disponível em: http://arquivopessoa.net/textos/277. Acesso em: 27 ago. 2016).

4 Importante salientar que a fala de Massaud Moisés é contextualizada nos cinquenta anos da morte de Fernando Pessoa, e que até a atualidade novos trechos/obras de Pessoa são achados, como o caso do bibliógrafo José Paulo Cavalcanti Filho que, em 2015, encontrou uma versão inédita do texto iniciado "Cada palavra dita é a voz de um morto", antes conhecido apenas em rascunhos. (MEIRELES, Maurício. Bibliófilo encontra versão inédita de poema de Fernando Pessoa. In: Folha de S. Paulo. 11 jun. 2016. Ilustrada. Disponível em: http://www1.folha.uol.com.br/ilustrada/2016/06/1780385-brasi-
} 
publicou em vida, sendo a maior parte de sua obra postumamente descoberta. Assim como Bandeira, Pessoa recorre a diversas imagens para tratar de variados temas, seja por sua voz ortônima ou por algum heterônimo, tais como o mar, a infância, a lua, a noite, o anoitecer, a escuridão (SCHÜLER, 1966).

Sobre a noite, Cleonice Berardinelli (1959 apud PITTELLA-LEITE, 2014, p. 129-130), observa que Fernando Pessoa, como "poeta angustiado pela busca do Mistério e pelos problemas do ser", prezava mais as "sombras ou claridade pálida e fria do luar", sendo “apreciável a insistência com que a noite aparece, tão presente, tão real, tão participante dos sentimentos do Poeta que lhe dá figura humana e divina e a ela se dirige com calor e ternura raros nele".

Essa noite tão presente que Berardinelli (1959) encontra em Pessoa e que é capaz de despertar calor e ternura no poeta, tal como em Bandeira, muitas vezes não pode ser dissociada da morte, seja ela benfazeja ou terrífica.

Destarte, o que podemos notar na poética bandeiriana é que a sua constituição é uma grande evolução no tratamento das imagens empregadas pelo "poeta menor". E no que diz respeito a da noite, ela representa não apenas uma aceitação, mas o entendimento da sua necessidade para o homem.

É por meio da noite que o poeta evoca a imagem da morte, trabalha-a, elevando-a, compreendendo-a. Essa ligação da noite com a morte se dá na construção do verso, e no próprio arcabouço imaginário humano. Por muito tempo a noite foi responsável por trazer à tona a impotência e a angústia no homem. Jean Delumeau (1989) explica que esses sentimentos se devem ao fato de, na noite, o homem ter a sua visão debilitada, de estar frente ao desconhecido, consequentemente, não compreendido. Quando nos aprofundamos na história da noite, encontramos nos mitos cosmogônicos uma explicação para sua ligação com a morte.

Para os gregos, a noite é denominada Nix, filha de Caos e irmã de Érebo, o negrume profundo. Na Teogonia, Hesíodo (2010) enuncia que do Caos

leiro-revela-caderno-com-versao-inedita-de-poema-de-fernando-pessoa.shtml. Acesso em: 26 set. 2016). nascem Geia, Tártaro e Eros, para, posteriormente, surgir Nix e seu irmão, de cujo amor nascerão Éter, brilhante, e Hêmera, a luminosidade do dia. Além disso, Hesíodo (2010) apresenta a descendência de Nix, que "gerou a odiosa Moira, a negra Quere e Tânatos. Também engendrou Hipno e a linhagem dos Sonhos. Sozinha, a deusa, a negra Nix, os concebeu a todos, sem deitar-se com ninguém" (2010, p. 33).

Segundo Junito Brandão, as primeiras gerações, concebidas sozinhas pela deusa, representam três aspectos diferentes da morte: Tânatos, Queres e Moîra. Tânatos "é o gênio masculino alado que personifica a Morte” (1986, p. 226); Queres são representadas como "gênios alados vestidas de preto, com longas unhas aduncas. Despedaçam os cadáveres e bebem o sangue dos mortos e feridos" (1986, p. 229), sendo mais tarde identificadas com as almas maléficas dos mortos; e a Moîra é o quinhão de vida, "a personificação do destino individual” (1986, p. 230) que conduz inevitavelmente à Morte.

A descendência de Nix, relatada por Hesíodo, justifica o fato de a noite despertar no homem grandes emoções, sendo, uma delas, o medo. Delumeau (1989) esclarece que a relação do ser humano com esse período foi complicada desde os primórdios, pois é durante a noite que as criaturas maléficas e predadoras saem para caçar (DURAND, 2002). Já chamara a atenção de C.G. Jung que

o nascer do sol fosse para o homem primitivo um momento de concentrada emoção, que parecia denso de significações secretas. De outra parte observara que durante a noite o primitivo estava sempre inquieto e medroso, receando perigos misteriosos, mas quando chegava o sol recuperava a segurança, tudo se lhe afirmava bom e belo. Deduziu Jung que a escuridão noturna corresponde à noite psíquica primordial, ao estado de inconsciência (JUNG apud SILVEIRA, 1974, p. 19).

Entretanto, nem sempre a noite é desencadeadora das mais temíveis emoções no homem. Ela também pode ser benfazeja e benéfica, trazendo aos seres a intimidade aconchegante. Notamos essa transformação da imagem noturna nos poemas de Manuel 
Bandeira, que não apenas atinge a maturidade na escrita, mas também demonstra, pela prática poética, a compreensão acerca da finitude a que os homens estão inevitavelmente ligados. Bandeira, em seus últimos poemas que tomam a noite e a morte como imagem e temática, fornece-nos não apenas a aceitação, mas uma reconciliação do homem e o seu fim.

Quando lemos em sequência os poemas "Dentro da noite", de A cinza das horas; "Noturno de Mosela" e "Noite morta", de O ritmo dissoluto; "Visita noturna", de Belo Belo e "Consoada”, de Opus 10, encontramos essa nova perspectiva da própria vida, que não pertence ao homem, mas que deve ser vivida em plenitude, para que a morte, a noite derradeira, possa encontrar o "eu-lírico" consciente de que cumpriu com o seu dever e não se sente amargurado por aquela visita, antes, está preparado, como podemos ver nos últimos versos do poema "Consoada":

O meu dia foi bom, pode a noite descer.

(A noite com os seus sortilégios.)

Encontrará lavrado o campo, a casa limpa,

A mesa posta,

Com cada coisa em seu lugar.

(BANDEIRA, 1993, p. 223)

Essa preparação para a morte percorre toda a poética de Bandeira. Em "Dentro da noite", encontramos um "eu-lírico" deslumbrado pela sedução da noite, em que "paira um sossego singular..." (BANDEIRA, 1993, p. 57) e ao mesmo tempo possui um ar angustiado, suplicante, que vibra dentro dessa noite, anunciando a presença da morte que não atende ao clamor do homem: "Ouve... Dir-se-ia uma garganta/ Súplice, triste, a soluçar/ Dentro da noite...” (1993, p. 58).

Formado por estrofes em quintilha, quarteto e sextilha, com versos de oito sílabas métricas, a exceção dos versos quinto, nono e décimo quinto, que parecem deslocados, dando a impressão de que não fariam parte daquelas estrofes, o poema conta com rimas ricas e consoantes

Dentro da noite a vida canta

E esgarça névoas ao luar...

Fosco minguante o vale encanta.
Morreu pecando alguma santa...

A água não pára de chorar.

(BANDEIRA, 1993, p. 57, grifo nosso).

As rimas do poema terminada em -anta, garantem uma fluidez aos versos, principalmente, pela nasalização da vogal a: canta, minguante, encanta, pecando, santa, tanta, infanta, garganta, que não ocorre só nas palavras finais de cada verso, mas também em seu interior. Essa nasalização proporciona um ritmo cantante que é angulado pela outra rima, -ar, sendo completado pelos versos nono e décimo quinto, cuja terminação -ite abaixa o tom do verso, trazendo o sombrio e tenebroso lamuriar da noite.

Quando nos deparamos com estruturas complexas e ao mesmo tempo simples, como o poema acima, compreendemos o motivo do poeta ser quase um mago, pois, "[e]mbora o poema não seja feitiço nem conjuro, à maneira de ensalmos e sortilégios o poeta desperta as forças secretas do idioma. O poeta encanta a linguagem por meio do ritmo. Uma imagem suscita outra" (PAZ, 2012, p. 63), o que no caso de Bandeira é constante. Sua noite busca a vida, que mingua e encontra a morte, que suscita o choro soluçante, ressoando no "eu-lírico" que reclama da sedução singular da morte. Já podemos encontrar, no primeiro livro de Bandeira, o clima que Antônio Olinto diz estar presente na obra do poeta pernambucano: "seus poemas buscam a noite, a sombra, o perdido, o esperado, o sofrido sem remissão, o que poderia ter sido e não foi, o que deixou um travo de angústia mansa no pensamento" (apud BANDEIRA, 1958, p. 131).

Na poética de Pessoa $^{5}$, encontramos quase sempre a imagem da noite associada à morte e à passagem do tempo, em uma busca por completar o sentido do ser. Segundo Schüler (1966, p. 70), o poeta “[n]ão se conforma com a noite que o sufoca [...] O que lhe importa é saber o sentido ou a falta de sentido de sua vida”. Assim, na noite pessoana habitam fantasmas e mistérios, mas o poeta não a teme, antes, deseja fundir-se a ela, ser cercado e envolto, como no soneto "Noite".

5 Para compreendermos a fluidez da imagem da noite, bem como a evocação da morte, não faremos distinção entre o ortônimo ou heterônimo ao tratarmos da poética produzida por Fernando Pessoa. 
Ó Noite maternal e relembrada

Dos princípios obscuros do viver;

Ó Noite fiel á escuridão sagrada

[...]

Ó Noite suave a alma fatigada

De querer na descrença poder crer;

Cerca-me e envolve-me... Eu não sou nada

Senão alguém que quer a ti volver...

Ó Noite antiga e misericordiosa,

Que seja toda em ti a indefinida

Existência que a alma me não gosa!

$5 / 3 / 1910$

(PESSOA, 2005, p. 89-90, grifo nosso).

O soneto em versos decassílabos, de rimas perfeitas e alternadas, apresenta um "eu-lírico" que não teme a noite, visto que ela é maternal, desejada e sagrada. Sua vontade é ser englobado por ela, tornando-se uma parte sua, deixando a sua condição vazia para pertencer à misericórdia noturna e, assim, se definir, convertendo-se em propriedade dela. Os adjetivos que enumeram essa Noite acrescentam-na um ar divino, rememorando a deusa da antiguidade, Nix, responsável tanto pelo surgimento de Éter como as mortes e os sonhos (HESÍODO, 2010).

No soneto datado de 14/3/1017 e iniciado por "SÚBITA mão de algum fantasma oculto", encontramos a noite novamente associada não apenas à morte, mas ao destino e à ligação com o indivisível. O "eu lírico" vê-se abandonado nos "braços da noite", reconhecendo a sua pequenez e a fragilidade humana em uma inexistência que o assombra.

\section{[...]}

Da noite não enxergo gesto ou vulto.

Mas um terror antigo, que insepulto Trago no coração, como de um trono Desce e se afirma em senhor e dono Sem ordem, sem meneio e sem insulto.

E eu sinto a minha vida de repente Presa por uma corda de Inconsciente A qualquer mão noturna que me guia.

Sinto que sou ninguém salvo uma sombra
De um vulto que não vejo e que me assombra, E em nada existo como a treva fria (PESSOA, 2016, p. 27, grifo nosso).

A noite já não é vista como maternal pelo "eu-lírico" nesse soneto em decassílabos de rimas perfeitas e intercaladas. Ela vem acompanhada do sentimento de terror, tal como para os antigos, que a temiam por sentirem-se desprotegidos. Esse parece também ser o clamor do "eu-lírico", que se vê não mais um homem, mas uma sombra, um espectro do que um dia fora e que não possui mais a existência. Ao contrário do soneto anterior, ele não quis se imiscuir à noite, mas se viu absorvido por ela.

Esse é a mesma situação "vivenciada" pelo "eu-lírico" no soneto datado de 31/08/1929. A noite volta a engolir tudo, contagiando o coração do poeta com o vazio que se alastra como as sombras noturnas.

Nas grandes horas em que a insónia avulta Como um novo universo doloroso, E a mente é clara com um ser que insulta O uso confuso com que o dia é ocioso,

Cismo, embebido em sombras de repouso Onde habitam fantasmas e a alma é oculta, Em quanto errei e quanto ou dor ou gozo Me farão nada, como frase estulta.

Cismo, cheio de nada, e a noite é tudo. Meu coração, que fala estando mudo, Repete seu monótono torpor

Na sombra, no delírio da clareza,

E não há Deus, nem ser, nem Natureza E a própria mágoa melhor fora dor 31/8/1929.

(PESSOA, 1993, p. 46).

Nesse soneto, a presença da noite, incorporada aos versos pela presença das sombras, conduzem ao tema da morte, esse lugar onde a alma é oculta, o coração torna-se mudo e o vazio domina a existência. A dominância da noite sobre o "eu-lírico" pode ser visto novamente no soneto "À Noite", em que o desejo de fundir-se à noite, e consequentemente à morte, transborda a alma do "eu-lírico". 
À NOITE

O silêncio é teu gémeo no Infinito. Quem te conhece, sabe não buscar. Morte visível, vens dessedentar $\mathrm{O}$ vago mundo, o mundo estreito e aflito.

Se os teus abismos constelados fito, Não sei quem sou ou qual o fim a dar A tanta dor, a tanta ânsia par

Do sonho, e a tanto incerto em que medito.

Que vislumbre escondido de melhores Dias ou horas no teu campo cabe? Véu nupcial do fim de fins e dores.

Nem sei a angústia que vens consolar-me. Deixa que eu durma, deixa que eu acabe E que a luz nunca venha despertar-me! 14/9/1919.

(PESSOA, 1993, p. 37, grifo nosso).

Novamente, o "eu-lírico" se vê frente à "Morte visível", contemplando seus "abismos constelados", buscando ser coberto por seu "Véu nupcial" de forma a abandonar a angústia que "tanta dor" lhe causa. A mesma vontade de ser tomado nos braços da morte pode ser vista no poema "Abdicação", em que o "eu-lírico" clama por se juntar à dama morte: "Toma-me, ó noite eterna, nos braços/ E chama-me teu filho" (PESSOA, 1995, p. 215). A noite retoma seu ar maternal, como salienta Donaldo Schüler (1966), em que o filho pode deixar-se amparar por seus braços e ali encontrar o conforto: "Despi a realeza, corpo e alma,/ E regressei à noite antiga e calma/ Como a paisagem ao morrer do dia" (1966, p. 215). Tal como o "eu-lírico" de "Noite", esse requer seu encontro com a "noite eterna", reconhecendo que, como homem, não possui nenhum poder sobre a morte, não é mais um rei, pois voluntariamente abandonou o seu trono.

A fusão do poeta com a noite é tema do poema "Velo, na noite em mim,/ Meu próprio corpo morto. / Velo, inútil absorto./ Ele tem o seu fim/ Inutilmente, enfim." (PESSOA, 1956, p. 81). O "eu-lírico" internaliza a noite, tomando-a para si, tornando-se noite e, por esse motivo, "corpo morto”. É a partir desse estado, “corpo morto", que o "eu-lírico" assimila a dinâmica da vida - ter um fim.

Nesse sentido, a poética de Pessoa aproxima-se da de Bandeira no sentido de perceber a morte como natural para o homem, como parte essencial para a sua própria compreensão. Para o poeta brasileiro, esse apreender e o preparar-se para a morte pode ser encontrado em "Visita noturna", em que o "eu-lírico" recebe uma visita inesperada, na calada da noite, que transforma a atmosfera de seu quarto, tal como já havia transformado em "Dentro da noite".

\section{Visita noturna}

Bateram à minha porta,

Fui abrir, não vi ninguém.

Seria a alma da morta?

Não vi ninguém, mas alguém

Entrou no quarto deserto

E o quarto logo mudou.

Deitei-me na cama, e perto

Da cama alguém se sentou.

Seria a sombra da morta?

Que morta? A inocência? A infância?

O que concebido, abortou,

Ou o que foi e hoje é só distância?

Pois bendita a que voltou!

Três vezes bendita a morta,

Quem quer que ela seja, a morta

Que bateu à minha porta

Rio, dezembro de 1947.

(BANDEIRA, 1993, p. 202, grifo nosso).

As rimas, seguidas pelo ritmo regular do heptassílabo, cujos únicos versos destoantes são o décimo primeiro e o décimo segundo, compostos em eneassílabos, que mantém a leitura estável, que demarca o questionamento que o "eu-lírico" se faz após abrir a porta. O "eu-lírico" se vê pronto para indagar-se na presença daquela "sombra", que interrompe a "incompletude" do "eu", marcado pelo enjambement nos versos: "Não vi ninguém, mas alguém/ Entrou no quarto deserto/ E o quarto logo mudou". A quebra da frase sintática também reforça uma ruptura do "eu”, que ressentido, "O que concebido, abortou,/ Ou 
o que foi e hoje é só distância?", e questionando-se, compreende a inevitabilidade do tempo. Entretanto, graças àquela invasão, o "eu-lírico" reconcilia-se com a invasora, que trouxera mais que fantasmas, mas um remédio, a calmaria suscitada pelos versos em redondilha maior que seguem à quebra do ritmo causada pelos versos de nove sílabas poéticas.

Gaston Bachelard (1978, p. 188), explica que a imagem "exprime-nos fazendo-nos o que ela exprime, ou seja, ela é ao mesmo tempo um devir da expressão e um devir de nosso ser", pois a imagem criada pelo poeta se enraíza no leitor, alcançando-o, sem que o leitor precise conhecer o passado daquela imagem. Não é preciso conhecer a batalha de Bandeira com a tuberculose, para compreender a força da morte em sua poesia. Mas é por meio de sua poesia que podemos compreender a reconciliação do poeta com o seu destino, que o visita, senta-se próximo a sua cama, e se torna bendita, "Três vezes bendita a morta”, desconhecida, mas não mais assustadora.

A morte, agora, é aguardada com o espírito de quem sabe que cumpriu a sua empreitada, que está pronto para sua partida, não possuindo remorsos. É esse o tom do poema “Consoada”. Não há mais choro, apenas um medo inicial, marcado pelo "talvez", logo desconstruído pela uniformidade criada pelo ritmo simétrico do verso "O meu dia foi bom, pode a noite descer.", que confirma a prontidão do "eu-lírico", para navegar não mais na noite sombria e tenebrosa, mas em uma noite aguardada em seus encantamentos, benfazeja em sua sedução.

A noite, como a morte, em Bandeira deixa de ser um espaço poético fechado e claustrofóbico, povoado por lamúrias e sombras, para, enfim, trazer a reconciliação, a certeza de que o eu-lírico cumpriu a sua missão, e está pronto para receber a sua visita noturna como se deve, com um sorriso no rosto e um cumprimento aprazível, afinal, ela já é aguardada: “- Alô, iniludível!” (BANDEIRA, 1993, p. 223).

Uma visita semelhante ocorre ao poeta português, no poema "Como a noite é longa!". O "eu-lírico" recebe a morte ao pé da cama e essa o aconchega como uma ama, ressaltando a característica materna da morte pessoana, que compreende o "eu-lírico" e ante atormentá-lo, conforta-o e pela música leva-o à morada do sono eterno.

Como a noite é longa!
Toda a noite é assim...
Senta-te, ama, perto
Do leito onde esperto.
Vem pr'ao pé de mim...
Amei tanta coisa...
Hoje nada existe.
Aqui ao pé da cama
Canta-me, minha ama,
Uma canção triste.
Era uma princesa
Que amou... Já não sei...
Como estou esquecido!
Canta-me ao ouvido
E adormecerei...
Que é feito de tudo?
Que fiz eu de mim?
Deixa-me dormir,
Dormir a sorrir
E seja isto o fim
(PESsoA, 1985, p. 43 , grifo nosso).

No poema acima, constituído de vinte versos distribuídos em cinco estrofes em quintilhas, de rimas ricas e pobres, interpolada e emparelhada, em redondilha menor, Pessoa desenvolve uma sonoridade reconfortante ao longo do poema, tal como a morte evocada, que não tem dor, não tem sofrimento, pois é benfazeja. Ambos os poetas, Fernando Pessoa e Manuel Bandeira, possuem uma íntima relação com a morte. Esse, por sua própria dinâmica com relação a ela, estava sempre a sua espera, aguardando-a a cada noite, enquanto aquele via-a chegar por todos os lados ao seu redor, seja levando familiares - seu pai e seu irmão, seja levando o amigo querido Mário de Sá-Carneiro. Enquanto Bandeira se reconcilia com a morte, não estando mais indefeso, Pessoa a internaliza, toma-a para si, naturaliza-a no seu labirinto de ser, afinal como ressalta Paz, "a imagem reconcilia 
os opostos", e o "poema é linguagem em tensão: em extremo de ser e em ser até o extremo" (2012, p. 117).

No tocante à imagem da noite, reparamos que nos dois poetas há uma metáfora da morte, uma morte ora perigosa, que agride o "eu-lírico", mostrando-se implacável e cruel, ora desejada, pois não se pode evitar a sua visita. Entretanto, nos poemas analisados, o cotejo entre o "eu-lírico" e a morte/noite parece seguir o mesmo caminho, naturalizando-se para eles, tornando-se uma visita agradável e aguardada.

\section{Referências}

BACHELARD, Gaston. A Filosofia do não; O novo espírito científico; A poética do espaço. Trad. Joaquim Jose Moura Ramos et al. São Paulo: Abril Cultural, 1978.

BANDEIRA, Manuel. Estrela da vida inteira. 20. ed. Rio de Janeiro: Nova Fronteira, 1993.

BANDEIRA, Manuel. Poesia e prosa. Rio de Janeiro: José Aguilar, 1958.

BRANDÃO, Junito de Souza. Mitologia grega. 18. ed. Petrópolis: Vozes, 1986. v. 1.

CAMPOS, Paulo Mendes. Manuel Bandeira fala de sua obra. Província de São Pedro, Porto Alegre, n. 13, p. 124-140, 1949.

DELUMEAU, Jean. História do medo no ocidente: 1300 -1800, uma cidade sitiada. Trad. Maria Lucia Machado. São Paulo: Companhia das Letras, 1989.

FORESTI, Nara Boneti. O entre espaços tempos e gêneros em Manuel Bandeira. Dissertação (Mestrado em Letras) Universidade Federal de Santa Catariana, Ilha de Santa Catarina, 2001. 166f. Disponível em: https://repositorio. ufsc.br/bitstream/handle/123456789/79871/180545.pdf?sequence=1. Acesso em: 24 jul. 2016. https://doi.org/10.21840/ siic/150549

HESÍODO. Teogonia; Trabalhos e Dias. Trad. Sueli Maria de Regino. São Paulo: Martin Claret, 2010.

MASSAUD, Moisés. Fernando Pessoa: o espelho e a esfinge. São Paulo: Cultrix: Editora da Universidade de São Paulo, 1988. https://doi.org/10.29182/hehe.v17i2.301

PAZ, Octavio. O arco e a lira. Trad. Ari Roitman e Paulina Wacht. São Paulo: Cosac Naify, 2012.

PESSOA, Fernando. Poesias Inéditas (1919-1930). Lisboa: Ática, 1956. Disponível em: http://arquivopessoa.net/textos/3643. Acesso em: 30 jun. 2016.

PESSOA, Fernando. Novas poesias inéditas. Org. Maria do Rosário Marques Sabino e Adelaide Maria Monteiro Sereno. 4. ed. Lisboa: Ática, 1993. Disponível em: http://arquivopessoa.net/textos/271. Acesso em: 30 jun. 2016.
PESSOA, Fernando. Poesias. 15. ed. Lisboa: Ática, 1995. Disponível em: http://arquivopessoa.net/textos/2027. Acesso em: 27 set. 2016.

PESSOA, Fernando. Poesia 1902-1917. Ed. Manuela Parreira da Silva, Ana Maria Freitas e Madalena Dine. Lisboa: Assírio \& Alvim, 2005.

PESSOA, Fernando. Poesia 1931-1935 e Não-datada. Ed. Manuela Parreira da Silva, Ana Maria Freitas e Madalena Dine. Lisboa: Assírio \& Alvim, 2006.

PESSOA, Fernando. Poesias. Org. Sueli Barros Cassal. Porto Alegre: L\&PM, 2016.

PITTELLA-LEITE, Carlos. Noturnos de Pessoa: Noite, Morte \& Temporalidade nos Sonetos de Fernando Pessoa. Pessoa Plural. [S. l.], n. 6, p. 125-151, outono de 2014. Disponível em: https://www.brown.edu/Departments/Portuguese_ Brazilian_Studies/ejph/pessoaplural/Issue6/PDF/I6Ao7. pdf. Acesso em: 25 jun. 2016. https://doi.org/10.17771/ pucrio.acad.30086

SCHÜLER, Donaldo. A racionalidade no ortônimo Fernando Pessoa. Organon: Revista da Faculdade de Filosofia, Porto Alegre, n. 11, p. 63-79, 1966. Disponível em: http://seer.ufrgs. br/index.php/organon/article/view/38958/24901. Acesso em: 15 ago. 2017. https://doi.org/10.22456/2238-8915.38958

SILVEIRA, Nise da. Jung Vida e obra. 3. ed. Rio de Janeiro: José Álvaro Editor, 1974.

SOUZA, Gilda de Mello e; CÂNDIDO, Antônio. Introdução. In: BANDEIRA, Manuel. Estrela da vida inteira. 20. ed. Rio de Janeiro: Nova Fronteira, 1993.

Recebido em: 24/4/2017.

Aprovado em: 15/10/2019.

\#27255

SEÇÃO: ENSAIOS

Endereço de correspondência:

Universidade Federal de Goiás - Faculdade de Letras Alameda Palmeiras, Qd. A, Câmpus Samambaia Goiânia-GO - CEP 74690-900 